\title{
The Yeast and Mammalian Ras Pathways Control Transcription of Heat Shock Genes Independently of Heat Shock Transcription Factor
}

\author{
DAVID ENGELBERG, ${ }^{1}$ EBRAHIM ZANDI,${ }^{2}$ CARL S. PARKER,${ }^{2}$ AND MICHAEL KARIN ${ }^{1}$ * \\ Department of Pharmacology, School of Medicine, Center for Molecular Genetics, University of California, San Diego, \\ La Jolla, California 92093-0636, ${ }^{1}$ and Division of Chemistry and Chemical Engineering, California Institute of \\ Technology, Pasadena, California $91125^{2}$
}

Received 10 January 1994/Returned for modification 23 February 1994/Accepted 27 April 1994

\begin{abstract}
Yeast strains in which the Ras-cyclic AMP (cAMP) pathway is constitutively active are sensitive to heat shock, whereas mutants in which the activity of this pathway is low are hyperresistant to heat shock. To determine the molecular basis for these differences, we examined the transcriptional induction of heat shock genes in various yeast strains. Activation of heat shock genes was attenuated in the strains in which the Ras-cAMP pathway is constitutively active. In contrast, in a strain deficient in cAMP production, several heat shock genes were induced by removal of cAMP from the medium. These results indicate that the Ras-cAMP pathway affects the induction of heat shock genes. In all of the mutants, heat shock transcription factor expression and activity were identical to those in wild-type cells. The response to heat shock in Ha-rastransformed rat fibroblasts was also studied. While no induction of Hsp68 was observed in Ha-ras-transformed cells, proper regulation of heat shock transcription factor was found. Therefore, in mammals, as in Saccharomyces cerevisiae, the Ras pathway controls the transcription of heat shock genes via a mechanism not involving the heat shock transcription factor.
\end{abstract}

The ras proto-oncogenes are highly conserved from yeasts to humans (reviewed in reference 12). These genes encode small membrane-associated GTP binding proteins that transduce signals generated at the cell surface to intracellular effectors $(3$, $7,24,59)$. The mammalian Ha-Ras protein seems to interact with the serine or threonine kinase Raf-1 $(43,77-79,85)$ and somehow leads to its activation. This results in activation of a protein kinase cascade $(18,73,83)$ that induces gene expression through phosphorylation of transcription factors (reviewed in reference 25). One transcription factor affected by Ha-Ras is c-Jun (6), and another is NF- $\mathrm{B}$ (17). In addition to positive modulation of the transcription factors' activity, $\mathrm{Ha}$ Ras may also negatively regulate certain transcription factors.

In the yeast Saccharomyces cerevisiae, the Ras effector is adenylyl cyclase, encoded by the $C Y R 1 / C D C 35$ gene (reference 75 [reviewed in references 12 and 22]). Thus the Ras proteins are involved in regulation of intracellular cyclic AMP (cAMP). In $S$. cerevisiae, cAMP is essential for traversing the start of the cell cycle at the $G_{1}$ phase. Mutants which cannot produce cAMP (for example, cyrl cells, in which the adenylyl cyclase is not active) require external cAMP for growth. In the absence of cAMP, these cells arrest in $\mathrm{G}_{1}$ or (in the case of diploid cells) sporulate even in rich medium $(41,64)$. cAMP-deficient cells are also resistant to nutrient starvation and are hyperresistant to heat shock $(26,65)$. On the other hand, mutants in which the Ras-cAMP pathway is constitutively active exhibit the opposite phenotype. Namely, they do not arrest in $\mathrm{G}_{1}$ upon starvation and are unable to sporulate. In addition, these cells cannot utilize nonfermentable sugars as carbon sources and are hypersensitive to nitrogen starvation and heat shock (31, $58,65,74)$. This phenotype is observed in strains that express the activated Ras $2^{\mathrm{Val}-19}$, which is equivalent to the mammalian Ha-Ras ${ }^{\text {Val-12, }}$, or the bcyl mutation, in which the catalytic

\footnotetext{
* Corresponding author. Phone: (619) 534-1361. Fax: (619) 5348158.
}

subunits of cAMP-dependent protein kinase (cPKA) are constitutively active (the $B C Y 1$ gene codes for the regulatory subunit of cPKA [74]).

Many aspects of Ras signalling are similar in yeasts and mammals $(2,20,40,62)$. It is not yet known, however, whether the effects of Ras activity on gene expression are similar in yeasts and in mammals. The fact that the effector of Ras in mammals is not adenylyl cyclase $(4,33)$ suggests that the downstream effects of Ras activation may not be evolutionarily conserved.

It was shown that expression of heat shock proteins (hsps) under nonshock conditions confers hyperresistance to heat shock $(27,42,56)$. Therefore, it seems reasonable that resistance and sensitivity to heat shock are mediated at the level of hsp gene transcription. Indeed, it was shown that cyrl cells express three proteins with a molecular mass of $72 \mathrm{kDa}(65)$. These proteins, which were probably hsps, were not induced in the $b c y 1$ strain (65). Other studies showed that one of the heat shock genes, $S S A 3$, was activated in the cyrl strain in the absence of heat shock $(9,80)$. Also, the $U B I 4$ gene, coding for polyubiquitin, was found to be regulated both by heat shock and cAMP (72). It is still not known, however, whether the Ras-cAMP pathway is a general regulator of hsp gene expression. It is also not known whether mammalian Ha-Ras activation also affects hsp gene expression. Furthermore, both in yeasts and in mammals, the relationship between the Ras pathway and the heat shock transcription factor (HSF [described below]) has not been investigated.

Induction of hsp genes in response to heat shock is a well-characterized and evolutionarily conserved phenomenon (reviewed in references 5, 34, and 35). The hsps exhibit a high degree of evolutionary conservation and, in addition to their protective role, are involved in regulation of normal cell functions $(32,35)$. Many hsps were identified in yeast cells, and some of the respective genes have been cloned. Some of these genes are highly homologous to each other and form subfam- 
TABLE 1. Yeast strains used in this study

\begin{tabular}{|c|c|c|}
\hline Strain & Relevant genotype & $\begin{array}{l}\text { Source or } \\
\text { reference }\end{array}$ \\
\hline SP1 & MATa his3 leu 2 ura 3 trp1 ade 8 can & 75 \\
\hline TK161R2V & $\begin{array}{l}\text { MATa his3 leu2 ura3 trp1 ade8 } \\
\quad \text { can1 RAS2 } 2^{\text {Val-19 }}\end{array}$ & 75 \\
\hline TTS121 & $\begin{array}{l}\text { MATa his3 leu2 ura3 trp1 ade8 } \\
\text { can1 bcy1::URA3 }\end{array}$ & 74 \\
\hline AM18-5CM1 & MAT $\alpha$ ura3 cyrl-1 & K. Matsumoto \\
\hline $411-40$ & $\begin{array}{l}\text { MATa ura1 his } 4 \text { trp1 adh1-11 adh3 } \\
\text { adr1-1::ADR1-TRP1 }\end{array}$ & C. Denis \\
\hline 660 & $\begin{array}{l}\text { MATa ura1 his } 4 \text { trpl adh1-11 adh3 } \\
\text { adr1-1::ADR1-5'-TRP1 }\end{array}$ & C. Denis \\
\hline
\end{tabular}

ilies (e.g., the $S S A$ subfamily of Hsp70 proteins and the HSP82 subfamily). In addition to the hsp genes, other genes which are not structurally related (e.g., STI1, enolase, and phosphoglycerate kinase) are also induced by heat shock $(46,51$ [reviewed in reference 38]).

The hsp genes contain one or more repeats of the heat shock response element (HSE) in their promoter region. The HSE is necessary and sufficient for heat shock-dependent transcription and is highly conserved $(15,49,50$ [reviewed in references 5 and 44]). It serves as a binding site for a specific heat shock-regulated transcription factor, $\operatorname{HSF}(50,76)$. The HSF gene has been cloned from various organisms $(14,21,30,52$, $60,61,70,82)$. The HSF acts as a multimer $(50,53,81)$ and in most organisms binds the HSE only upon heat shock $(36,67$, 68 ). The $S$. cerevisiae HSF (yHSF) binds DNA before and after heat shock (68) and is phosphorylated in response to heat shock $(68,70)$. The role of this phosphorylation has not been established. Little is known about the signal transduction pathway that senses the stress signal and leads to activation of HSF in yeasts or in higher eukaryotes.

We found that the mutations in the Ras-cAMP pathway had dramatic effects on induction of hsp genes. These effects are not mediated via yHSF, since its expression level and biological activity were found to be similar in all of the different strains. It seems, therefore, that the Ras-cAMP pathway controls expression of hsp genes via another factor or other factors. We also found that mammalian Ha-Ras affects hsp gene expression in fibroblasts. As in yeasts, the effect of mammalian Ha-Ras on hsp genes was not transmitted via HSF.

\section{MATERIALS AND METHODS}

Yeast strains and culture. Yeast strains used in this study are described in Table 1 . Yeast strains were commonly grown on YEPD (1\% yeast extract, $2 \%$ peptone, $2 \%$ glucose). Strains harboring the plasmid pCYC1-HSE-LacZ were grown on SD medium $(0.17 \%$ yeast nitrogen base, $0.5 \%$ ammonium sulfate, $2 \%$ glucose) plus the appropriate metabolites and lacking leucine. The cyrl strain was grown in the presence of $1.0 \mathrm{mM}$ cAMP. The viability of the mutants at different heat shock temperatures was tested in two ways. First, the mutants were grown on solid YEPD plates for 3 days at $30^{\circ} \mathrm{C}$ and were replica plated onto different plates that were prewarmed for 1 $\mathrm{h}$ at different temperatures (see Fig. 1). All plates were subsequently incubated at the different temperatures for $\mathbf{3 0}$ min, followed by incubation at $30^{\circ} \mathrm{C}$ for 3 days. In a second assay, cells were grown in YEPD liquid medium at $23^{\circ} \mathrm{C}$ to $10^{7}$ cells per $\mathrm{ml}$. The cultures were split, and one-half was transferred to a prewarmed water bath $\left(39^{\circ} \mathrm{C}\right)$ for $20 \mathrm{~min}$. Following this treatment, the viability of shocked and nonshocked cells was compared by plating cells (after proper dilutions) on solid YEPD plates at $30^{\circ} \mathrm{C}$ and counting the colonies 3 days later.

Mammalian cell culture. Rat FR3T3 fibroblasts and Ha-rastransformed FR3T3 cells were grown on Dulbecco's modified Eagle's medium supplemented with $10 \%$ fetal calf serum.

Heat shock treatment and RNA preparation. Yeast cultures were grown under vigorous shaking at $23^{\circ} \mathrm{C}$ to about $10^{7}$ cells per ml. Half of the culture was then transferred to a prewarmed water bath $\left(39^{\circ} \mathrm{C}\right)$, while the other half remained at $23^{\circ} \mathrm{C}$. After $20 \mathrm{~min}$, cells were harvested and total RNAs were prepared as described previously (54). The $R A S 2^{\mathrm{Val}-19}$ and bcy1 mutants survived this treatment (see Results [Fig. 1]). Cells of the cyr1 strain were grown to about $10^{6}$ cells per ml at $23^{\circ} \mathrm{C}$ in the presence of $1.0 \mathrm{mM}$ cAMP. The cells were then collected, washed with water, resuspended in YEPD medium, and split. One-half was supplemented with $1.0 \mathrm{mM}$ cAMP. Both cultures were allowed to grow for $6 \mathrm{~h}$ at $23^{\circ} \mathrm{C}$. Next, each culture was split, and one-half was transferred to $39^{\circ} \mathrm{C}$ for 20 min while the other half remained at $23^{\circ} \mathrm{C}$. For glucose starvation experiments (see Fig. 4B), cyrl and SP1 (wild-type) cells were grown on YEPD medium to $10^{7}$ cells per ml. A sample was removed for RNA preparation, and the rest of the cultures were washed with water and resuspended in the same volume of YEPD medium but containing $0.02 \%$ glucose. cyr1 cells were supplemented with $1 \mathrm{mM}$ cAMP. Cells were allowed to grow for another $15 \mathrm{~h}$. During that time, cell number did not change significantly. The cyrl culture was then split, and one-half was transferred to $39^{\circ} \mathrm{C}$ for $20 \mathrm{~min}$ before RNA was prepared.

Rat fibroblasts were grown at $37^{\circ} \mathrm{C}$ to 80 to $90 \%$ confluency, and then they were transferred to $42^{\circ} \mathrm{C}$ for the indicated time periods. Cells were allowed to recover at $37^{\circ} \mathrm{C}$ for $45 \mathrm{~min}$ before RNA and nuclear extracts were prepared. RNA was prepared by phenol extraction of cytosolic fractions (1).

RNA analysis. (i) Primer extension analysis. For primer extension analysis, $15 \mu \mathrm{g}$ of total RNA was incubated with 1 to $3 \mathrm{ng}$ of ${ }^{32} \mathrm{P}$-labeled specific oligonucleotide $(150,000 \mathrm{cpm} / \mathrm{ng})$ in the presence of $133 \mathrm{mM} \mathrm{KCl}$ at $70^{\circ} \mathrm{C}$ for $3 \mathrm{~min}$. The incubation mixture was allowed to cool slowly to $37^{\circ} \mathrm{C}$, when avian myeloblastosis virus reverse transcriptase was added and used as described previously (55). The primer extension products were separated on a $6 \%$ polyacrylamide- $7.0 \mathrm{M}$ urea gel.

(ii) $\mathrm{S} 1$ analysis. For $\mathrm{S} 1$ analysis of the rat $H S P 68$ gene, $20 \mu \mathrm{g}$ of RNA was coprecipitated with 0.1 pmol of oligonucleotide $(100,000 \mathrm{cpm})$. Samples were denatured, hybridized, and subsequently treated with $\mathrm{S} 1$ nuclease as described previously (55). S1 digestion products were ethanol precipitated and separated on an $8 \%$ polyacrylamide-7.0 M urea gel. The results of the primer extension and S1 analyses were quantitated with an LKB densitometer.

To distinguish between the highly homologous genes, specific oligonucleotides to be used as primers were designed and synthesized. The sequences of these oligonucleotides were complementary to the relevant RNAs in regions in which the homology to other heat shock genes is minimal. The following oligonucleotides were used: SSA1, 5'-CGTCGAAAACGG TATTCGAAGGATTCAT-3' (66); $S S A 2,5^{\prime}$-CGAAAACA GTGTTAGCTGGG-3' (66); $S S A 3,5^{\prime}$-CACGAGTAAGTTG TTCCC-3' (8); SSA4, 5'-AGCATCGTTCGTCACTTCTG GATCA-3' (10); HSC82, 5'-TATCTAAAGCATCGGAGG CG-3' (11); HSP26, 5'-GGTGCGTAGCCTCTTAAGCCG-3' (71); HSP104, 5'-GATGTTGATGATCCGAAGCC-3' (48); rat $H S C 73,5^{\prime}$-CCGCAGGTCCCTTAGACATG-3' (69); and mouse $H S P 68$ (used for S1 analysis), 5'-GGGCGCCGGCGG GATGCCGCTCAGTTCGAAGCGCCCCAGCAGGTTGT TGTCGCGCGTCATGG-3' (37). 
Oligonucleotides were synthesized with a gene assembler and were subsequently purified on a $12 \%$ polyacrylamide -7.0 $\mathrm{M}$ urea gel as described previously (55).

Whole cells and nuclear extracts: DNA binding assays. Yeast cultures were grown and heat shocked as described for RNA preparations. For whole-cell extracts, 200-ml cultures were used. Cells were collected and washed with $50 \mathrm{ml}$ of 200 $\mathrm{mM}$ Tris (pH 8.0), $400 \mathrm{mM}\left(\mathrm{NH}_{4}\right)_{2} \mathrm{SO}_{4}, 10 \mathrm{mM} \mathrm{MgCl}, 10 \%$ glycerol, $7.0 \mathrm{mM} \beta$-mercaptoethanol, $1.5 \mathrm{mM}$ phenylmethylsulfonyl fluoride, $150 \mu \mathrm{g}$ of leupeptin per $\mathrm{ml}, 25 \mu \mathrm{g}$ of pepstatin A per ml, $25 \mu \mathrm{g}$ of benzamidine- $\mathrm{HCl}$ per $\mathrm{ml}, 5.0 \mu \mathrm{g}$ of antipain per ml, $5.0 \mu \mathrm{g}$ of chymostatin per $\mathrm{ml}, 10 \mu \mathrm{g}$ of aprotinin per ml, $300 \mu \mathrm{g}$ of 1,10-o-phenanthroline per $\mathrm{ml}$, and $50 \mu \mathrm{g}$ of bestatin per $\mathrm{ml}$. The pellets were resuspended in 300 $\mu \mathrm{l}$ of $40 \mathrm{mM}$ HEPES ( $N$-2-hydroxyethylpiperazine- $N^{\prime}$-2-ethanesulfonic acid [pH 8.0])-5.0 mM EDTA-20\% glycerol-7.0 $\mathrm{mM} \beta$-mercaptoethanol plus the protease inhibitors stated above. The suspensions (each in a volume of about $500 \mu \mathrm{l}$ ) were transferred to Eppendorf tubes. Acid-washed glass beads $(1.0 \mathrm{~g}$ [ 0.4 to $0.6 \mu \mathrm{m}$ in diameter; SIGMA] ) were added and the tubes were vigorously vortexed for $30 \mathrm{~s}$ eight times with a period of $30 \mathrm{~s}$ on ice between each vortexing. The tubes were then centrifuged $(12,000 \times g$ for $5 \mathrm{~min})$, and the supernatants were collected and recentrifuged at $150,000 \times g$ for $1 \mathrm{~h}$ at $4^{\circ} \mathrm{C}$. The supernatants were collected and kept at $-70^{\circ} \mathrm{C}$ until use. The protein concentrations of the extracts were between 3 and $15 \mathrm{mg} / \mathrm{ml}$. DNA binding activity was not affected by several cycles of thawing and freezing the extracts. For DNA binding analysis, $15 \mu \mathrm{g}$ of extract was incubated with $1.0 \mathrm{ng}$ of nick-translated, double-stranded oligonucleotide (5'-GCGC CTCGAATGTTCGCGAAAAGAGCG-3' and 5'-GCGCTC TTTTCGCGAACATTCGAG-3' $[100,000 \mathrm{cpm} / \mathrm{ng}]$ ) in the presence of $1.0 \mathrm{mM}$ EDTA-1.0 mM dithiothreitol-4\% Ficoll$400-4.0 \mu \mathrm{g}$ of bovine serum albumin (fraction V; SIGMA) per ml-2.0 $\mu \mathrm{g}$ of poly(dI-dC)-28 mM KCl-0.5 $\mu \mathrm{g}$ of supercoiled plasmid pGCRE-CYC1-LacZ (23) in a volume of $40 \mu$ l. The reaction mixture was incubated at $25^{\circ} \mathrm{C}$ for $15 \mathrm{~min}$ and then loaded on a $4 \%$ polyacrylamide gel. The running buffer was $0.25 \times$ Tris-borate-EDTA, and the gel was run for at least $6 \mathrm{~h}$ at $100 \mathrm{~V}$. For competition assays (see Fig. 7), a reaction mixture in a volume of $160 \mu \mathrm{l}$ was allowed to equilibrate for 20 min at $25^{\circ} \mathrm{C}$, when cold oligonucleotide $(5.0 \mathrm{ng}$ ) was added. Forty-microliter samples were loaded on the gel at the indicated time points. For alkaline phosphatase treatment, $15 \mu \mathrm{g}$ of extracts was incubated in $23 \mathrm{mM}$ HEPES ( $\mathrm{pH} \mathrm{8.0),} 3 \mathrm{mM}$ $\mathrm{MgCl}_{2}, 50 \mathrm{mM} \mathrm{NaCl}$, and $1 \mathrm{U}$ of alkaline phosphatase (Boehringer Mannheim) for $30 \mathrm{~min}$ at $30^{\circ} \mathrm{C}$.

Nuclear extracts of FR3T3 cells were prepared by resuspending the nuclei (1) in $100 \mu$ l of $20 \mathrm{mM}$ HEPES $(\mathrm{pH}$ 7.9)-25\% glycerol-0.4 M NaCl-1.0 mM EDTA-1.0 mM EGTA-2.5 mM dithiothreitol-5.0 $\mu \mathrm{g}$ of leupeptin per ml-1.5 $\mathrm{mM}$ phenylmethylsulfonyl fluoride and incubating the mixture for $30 \mathrm{~min}$ at $4^{\circ} \mathrm{C}$. The mixture was centrifuged, and the supernatant was used for bandshift experiments under the same conditions described above for the yeast extracts.

Western blotting (immunoblotting). Whole-cell extracts (120 $\mu \mathrm{g}$ of each preparation) were resolved on a sodium dodecyl sulfate-polyacrylamide gel electrophoresis (SDSPAGE) gel (8\% polyacrylamide) and transferred to nitrocellulose by electroblotting for $2 \mathrm{~h}$ (1). After blocking, the filter was incubated with anti-yHSF monoclonal antibodies (82). The filter was subsequently incubated with peroxidase-conjugated goat antimouse immunoglobulin G, and bound antibodies were detected with an enhanced chemiluminescence system (Amersham).

Plasmids, yeast transformation, and $\beta$-galactosidase assay.

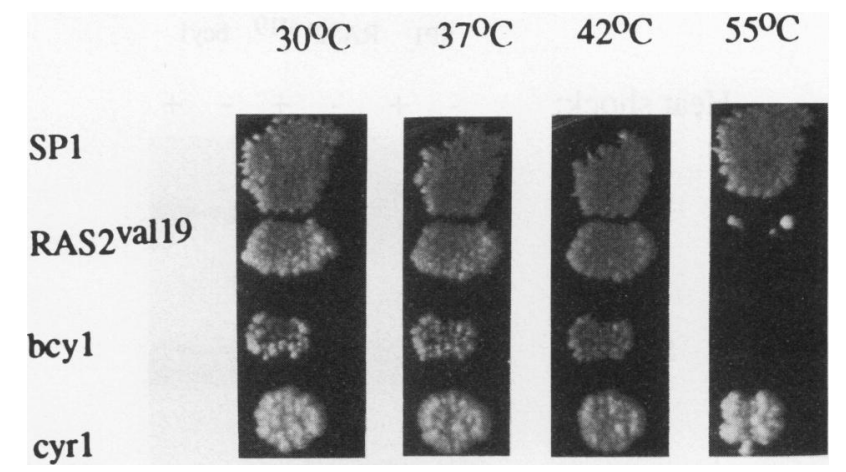

FIG. 1. Heat shock viability assay for the strains used in the study. The master plate was grown on YEPD at $30^{\circ} \mathrm{C}$ for 3 days and replica plated onto different plates prewarmed to the indicated temperatures. Each plate was further incubated at the indicated temperature for 30 min and was subsequently incubated for 3 days at $30^{\circ} \mathrm{C}$.

The pCYC1-HSE-LacZ construct was described previously (82). The plasmid was introduced into yeast cells by using the $\mathrm{LiCl}_{2}$-polyethylene glycol method (29), and colonies were collected on SD plates lacking leucine. To measure $\beta$-galactosidase activity, cells were grown in minimal medium and heat shocked as described previously (47), but the heat shock period was $20 \mathrm{~min}$. After treatment, cells were collected, resuspended in buffer Z, and assayed as described previously (1).

\section{RESULTS}

The $R A S 2^{\text {Val-19 }}$ and bcyl strains survive heat shock of up to $42^{\circ} \mathrm{C}$. Cells that carry the $R A S 2^{\text {Val-19 }}$ or the $b c y 1$ mutations were shown to be heat shock sensitive $(58,74,75)$. Namely, they could not survive short exposure to $55^{\circ} \mathrm{C}$. To find heat shock conditions under which these strains remain viable, the mutants were heat shocked either after replica plating or in liquid culture (see Materials and Methods). Figure 1 shows the results of the replica plating assay. All of the strains survived heat shock treatment of up to $42^{\circ} \mathrm{C}$, but as expected, $R A S 2^{\mathrm{Val}-19}$ and $b c y 1$ cells did not survive exposure to $55^{\circ} \mathrm{C}$. In the liquid culture assay, all of the mutants usually showed $100 \%$ viability after heat shock of $39^{\circ} \mathrm{C}$, although in some experiments the $b c y 1$ strain showed reduced viability. Reduced viability of this strain was also observed for cultures grown at $23^{\circ} \mathrm{C}$ and therefore was not a result of the heat shock. On the basis of these observations, in subsequent experiments, all strains were treated at $39^{\circ} \mathrm{C}$ for $20 \mathrm{~min}$ for inducing the heat shock response.

The resistance of the $R A S 2^{\mathrm{Val}-19}$ and $b c y 1$ strains to heat shock at $42^{\circ} \mathrm{C}$ suggests that the biochemical machinery responsible for protecting the cells during heat shock is not completely defective in these mutants. Interestingly, the $b c y 1$ strain was more sensitive to heat shock than the $R A S 2^{\mathrm{Val}-19}$ strain.

Induction of hsp gene transcription is attenuated in the $\boldsymbol{R A S 2}{ }^{\mathrm{Val}-19}$ and bcy1 strains. To test the transcriptional response of the $R A S 2^{\mathrm{Val}-19}$ and $b c y l$ strains to heat shock, we analyzed the induction of hsp genes by primer extension (Fig. 2). Quantitative presentation of these data is depicted in Fig. 3 . It can be seen that the level of induction of all hsp genes analyzed is reduced in the mutant strains. Since the levels of $S S A 2$ mRNA, which is a constitutively expressed member of the $H S P 70$ family (34), were similar in all of the strains, $S S A 2$ mRNA was used for normalizing the results presented in Fig. 3 . The bcyl mutation had a more severe effect on the shock response than the $R A S 2^{\mathrm{Val}-19}$ mutation. These differences 


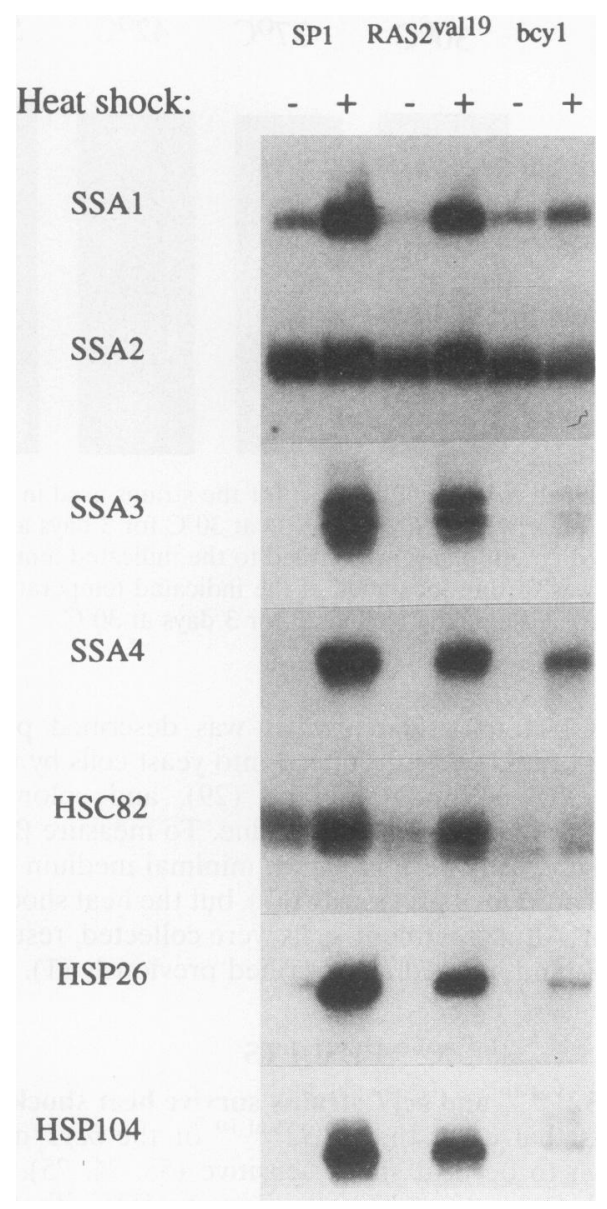

FIG. 2. Effect of the RAS2 $2^{\text {Val-19 }}$ and $b c y 1$ mutations on the heat shock response. Primer extension analysis of RNA prepared before $(-)$ or after $(+)$ heat shock treatment of the SP1 (lanes 1 and 2),

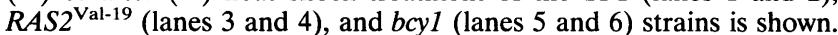
The sequences of the specific oligonucleotides used as primers are described in Materials and Methods.

match the effect of the two mutations on heat resistance described above.

Transcription of hsp genes in the cyrl mutant is induced at $23^{\circ} \mathrm{C}$ upon cAMP depletion. In contrast to the $R A S 2^{\mathrm{Val}-19}$ and bcyl strains, mutants in the $C Y R 1$ gene are more heat resistant than wild-type cells $(26,65)$. The cyrl strain carries, in addition to a mutation in its $c y r 1$ gene, other mutations that confer its ability to incorporate cAMP from the growth medium (41). This property of the cyr1 strain allows accurate analysis of the effect of cAMP on gene expression. To check whether the increased resistance of the cyrl strain correlates with expression of hsp genes, cyrl cells grown in the presence or absence of cAMP were analyzed for hsp gene expression (Fig. 4A). While the presence or absence of cAMP in the growth medium had no effect on the induced level of the various hsp genes analyzed, we found that removal of cAMP led to partial induction of $S S A 1, S S A 3$, and $H S P 26$ at $23^{\circ} \mathrm{C}$. A previous study described the induction of $S S A 3$ by cAMP depletion but assumed that this induction was unique to this hsp gene (80). Our results suggest that many hsp genes, members of different subfamilies, are regulated by cAMP.

cAMP is essential for the start of the cell cycle, and in the absence of cAMP, yeast cells arrest in $G_{1}$. It was important,

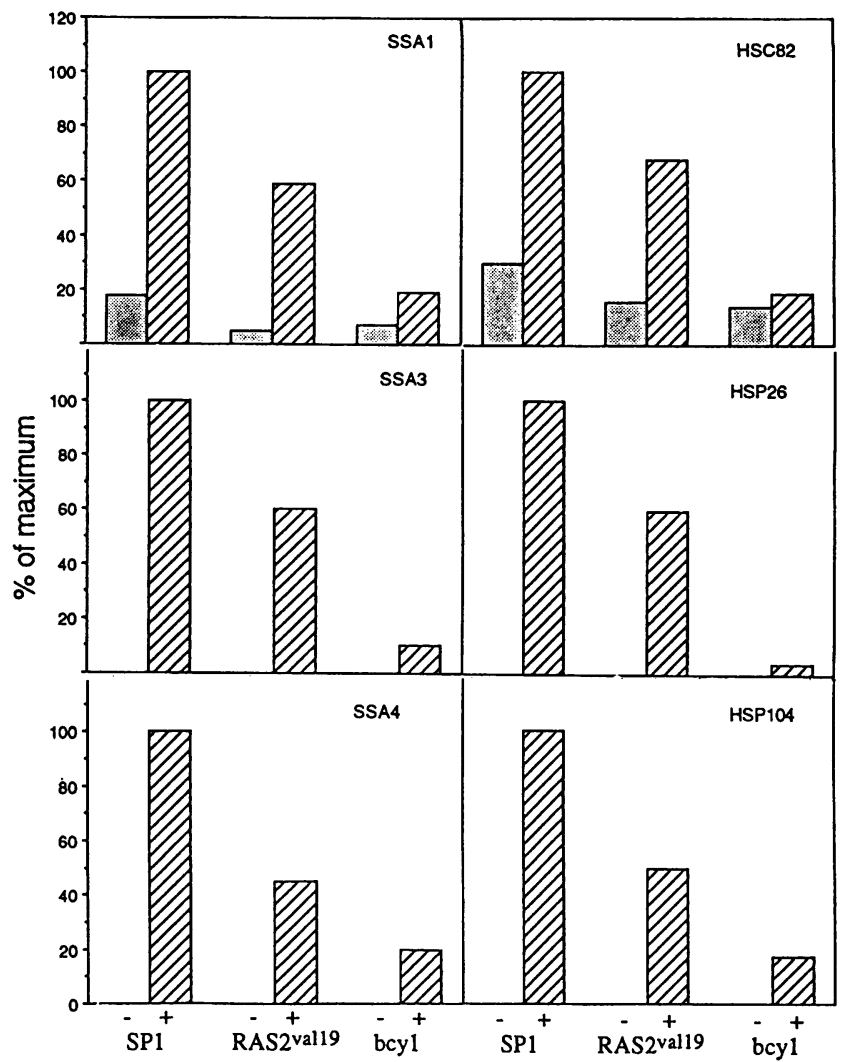

FIG. 3. Quantitation of heat shock gene expression in the $R A S 2^{\text {Val-19, }}$ $b c y 1$, and SP1 strains. Data from two independent experiments (one is shown in Fig. 2) were quantitated with a densitometer scanner. The averages of the two measurements are shown. The expression level of $S S A 2$ in each case was used to normalize the expression of the other genes. - and + , before and after heat shock, respectively.

therefore, to check whether the induction of $S S A 1, S S A 3$, and HSP26 in cyrl cells is regulated directly by cAMP depletion or is due to cell cycle arrest. To address this issue, we induced cell cycle arrest by glucose starvation (in the presence of cAMP [see Materials and Methods for experimental details]) and measured heat shock gene expression. Figure $4 B$ shows that $G_{1}$ arrest of cyrl cells by glucose starvation, in the presence of cAMP, did not result in hsp gene induction. On the other hand, wild-type cells that were arrested by glucose starvation did induce these genes (Fig. 4B, lane 5). The wild-type cells cannot absorb cAMP from the medium, and glucose starvation results in decreased intracellular cAMP levels $(12,22)$. The reduced levels of $G_{1}$ cyclin mRNA (data not shown) confirmed that both the cyrl and the SP1 strains were arrested at early $G_{1}$ stage (45). These results suggest that expression of $S S A 1$, $S S A 3$, and $H S P 26$ is not mediated by $\mathrm{G}_{1}$ arrest per se but is a specific response to cAMP depletion.

yHSF is correctly expressed and regulated in all of the mutants. Next, we examined whether the Ras-cAMP pathway modulates the heat shock response by regulating the expression or activity of yHSF. We checked first whether the transcription of the yHSF gene is suppressed during heat shock in the $R A S 2^{\mathrm{Val}-19}$ and $b c y 1$ strains. Transcription of the yHSF gene initiates at five major initiation sites, one of which (located at approximately -135) was elevated after heat shock (data not shown). The overall expression level was somewhat lower in the $b c y 1$ strain (about $70 \%$ of the wild-type level) but 
A.

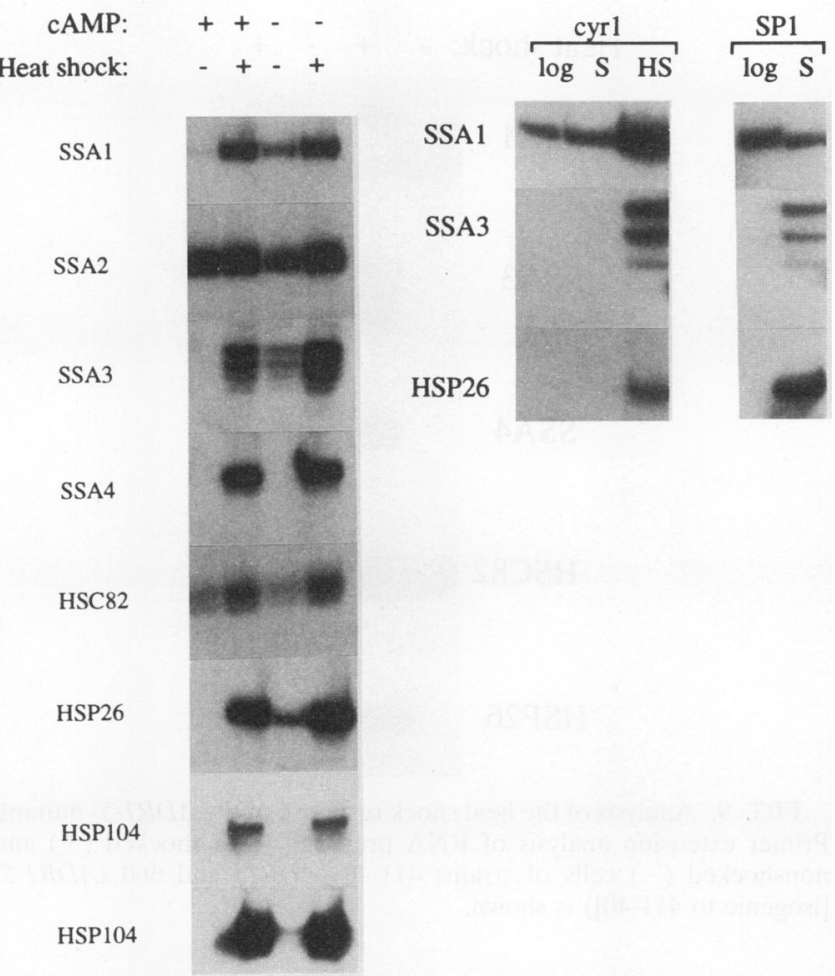

FIG. 4. Effects of cAMP and glucose starvation on the expression of heat shock genes. (A) Expression of heat shock genes in the cyrl strain grown in the presence (lanes 1 and 2) or absence (lanes 3 and 4) of cAMP before (lanes 1 and 3 ) and after (lanes 2 and 4 ) heat shock (see Materials and Methods for experimental details). For HSP104, two different exposures (1 and $3 \mathrm{~h}$ ) of the same gel are shown. (B) Expression of heat shock genes in the cyrl strain (lanes 1 to 3 ) and in the SP1 strain (lanes 4 and 5) during logarithmic growth (log; lanes 1 and 4 ), after $15 \mathrm{~h}$ of glucose starvation (S; lanes 2 and 5), and after heat shock of the starved cells (HS; lane 3). For details on starvation conditions, see Materials and Methods.

was not affected by heat shock (data not shown). Analysis of the yHSF protein level by Western blotting (Fig. 5) reveals that the levels of protein expression are similar in all of the strains and are not affected by heat shock. The slower mobility of yHSF after heat shock (Fig. 5) is a result of a phosphorylation event which occurs upon heat shock (68, 70 [described below]).

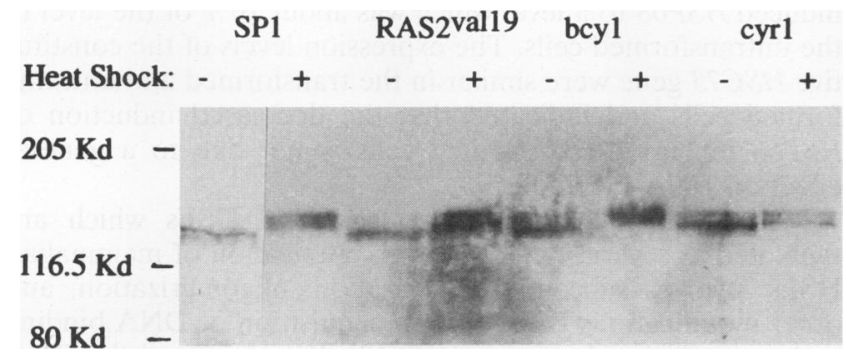

FIG. 5. Analysis of the expression of yHSF in the different strains. Whole-cell extracts prepared before $(-)$ or after $(+)$ heat shock from the indicated strains were resolved on an SDS-PAGE gel (8\% polyacrylamide), transferred to nitrocellulose, and probed with anti-yHSF monoclonal antibodies (82). The migration positions of molecular mass standards are shown on the left-hand side in kilodaltons.
A.

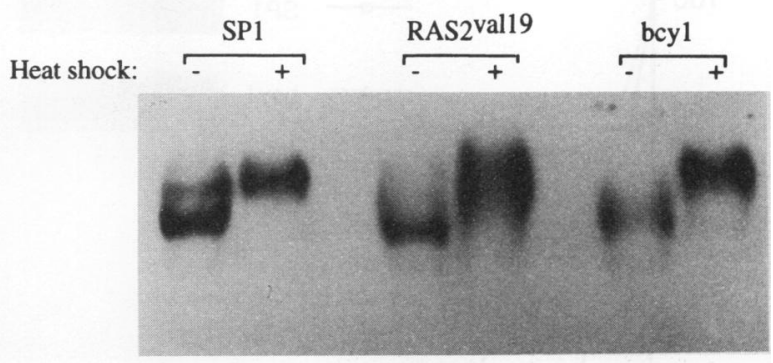

B.

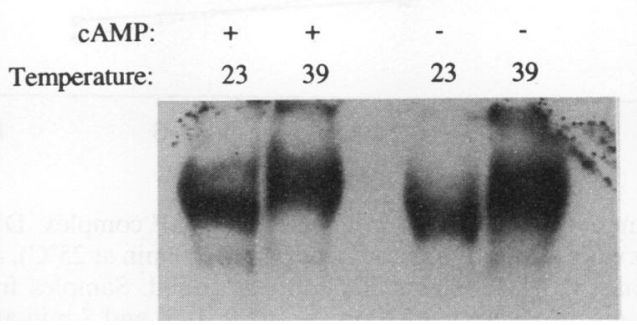

FIG. 6. yHSF DNA binding activity in various mutants of the Ras-cAMP pathway. (A) Bandshift assay with whole-cell extracts of

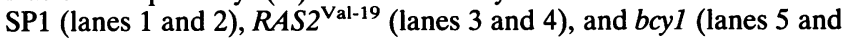
6) strains before (- [lanes 1,3, and 5]) and after ( + [lanes 2, 4, and 6]) heat shock. (B) Bandshift assay with whole-cell extracts prepared from cyrl cells grown in the presence $(+)$ or absence $(-)$ of cAMP at either 23 or $39^{\circ} \mathrm{C}$, as indicated. These figures show only the segment of the autoradiogram corresponding to the yHSF-HSE complex.

Next, we measured yHSF DNA binding activity in the various strains. yHSF binds to DNA before and after heat shock, while its electrophoretic mobility is retarded after heat shock (68). This retardation is a result of yHSF phosphorylation that occurs concomitantly with its activation $(68,70)$. As shown in Fig. 6A, yHSF binding activity was similar in SP1, $R A S 2^{\text {Val-19 }}$ and $b c y 1$ cells before and after heat shock and its electrophoretic mobility was retarded to a similar extent. In the cyrl strain, the removal of cAMP did not affect the binding activity of yHSF or its electrophoretic mobility at $23^{\circ} \mathrm{C}$, while heat shock resulted in retarded mobility (Fig. 6B). The retarded mobility of the yHSF-HSE complex did indeed reflect increased protein phosphorylation, because alkaline phosphatase treatment increased the mobility of the complex formed by extracts of heat-shocked cells to the same level as that of the control cells (data not shown).

Although the yHSFs in all of the mutants exhibited similar levels of HSE binding activities, there could be subtle differences in the dissociation constants of the factor expressed in each mutant. To address this possibility, cold HSE oligonucleotide was added to the DNA binding reaction mixtures after they reached steady state $\left(20 \mathrm{~min}\right.$ at $\left.25^{\circ} \mathrm{C}\right)$. At given time points, a sample from each reaction mixture was removed and analyzed by gel electrophoresis. The decreases in radioactivity associated with the yHSF-HSE complex were similar in both strains (Fig. 7). In fact, it appears that the dissociation rate in the bcy1 extract is somewhat slower than that in the SP1 extract. Therefore, the $b c y 1$ mutation does not decrease the stability of the yHSF-HSE complex.

To test the function of the yHSF in the different mutants in vivo, we used a reporter gene (pCYC-HSE-LacZ) that contains artificial HSEs upstream of the minimal promoter of the 


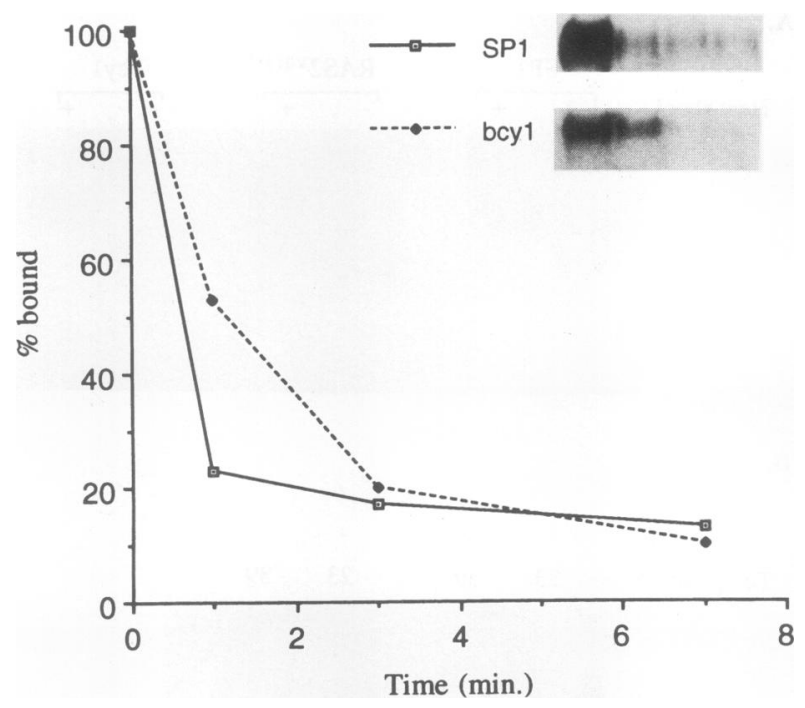

FIG. 7. Kinetics of dissociation of the HSE-yHSF complex. DNA binding assays were allowed to reach steady state $\left(20 \mathrm{~min}\right.$ at $\left.25^{\circ} \mathrm{C}\right)$, and then nonradioactive HSE oligonucleotide was added. Samples from each reaction mixture were loaded on the gel $0,1,3$, and $7 \mathrm{~min}$ after addition of the cold oligonucleotide.

CYC1 gene. Similar constructs were used previously to study yHSF activity $(30,47,68)$. As shown in Fig. 8, this reporter gene was inducible by heat shock in both $R A S 2^{\text {Val-19 }}$ and $b c y 1$ cells. The induction in $R A S 2^{\text {Val-19 }}$ was essentially equal to that in SP1, but the induction in bcy1 was about $75 \%$ of the induction in the wild-type strain. This small decrease in yHSF activity cannot explain the strong effect of the bcyl mutation on induction of endogenous hsp genes. Collectively, these results suggest that the Ras-cAMP pathway does not affect induction of hsp genes via yHSF.

Adr1 is not a regulator of the heat shock genes. So far only one yeast transcription factor, Adr1, was shown to be regulated by cPKA (13). Adr1 is an activator of the glucose-repressed $A D H 2$ gene, and its activity is suppressed in the bcy1 strain (13,

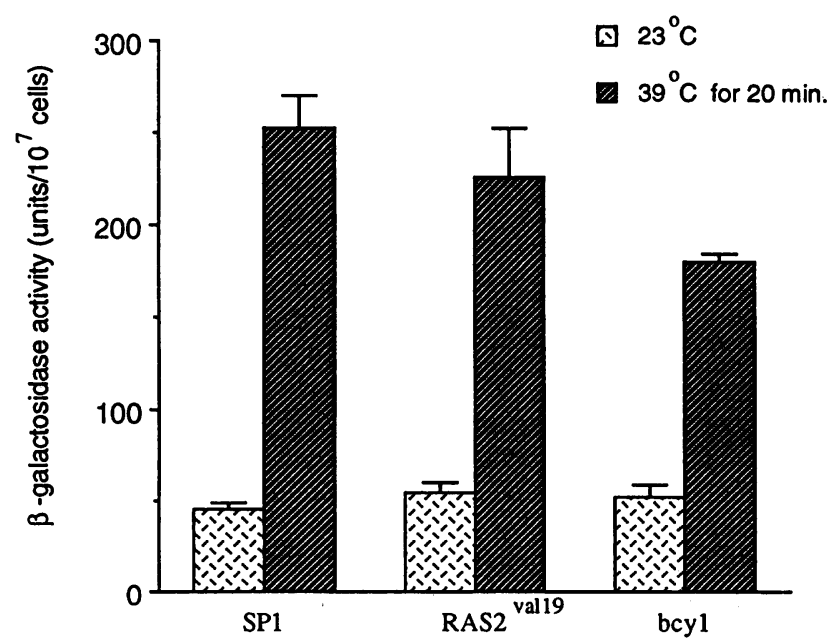

FIG. 8. Measurement of the activity of a CYC1-HSE-LacZ reporter gene in SP1, RAS2 $2^{\mathrm{Val}-19}$, and $b c y 1$ strains. $\beta$-Galactosidase activity was measured for lysed cells that were previously grown at $23^{\circ} \mathrm{C}$ or heat shocked as described in Materials and Methods.

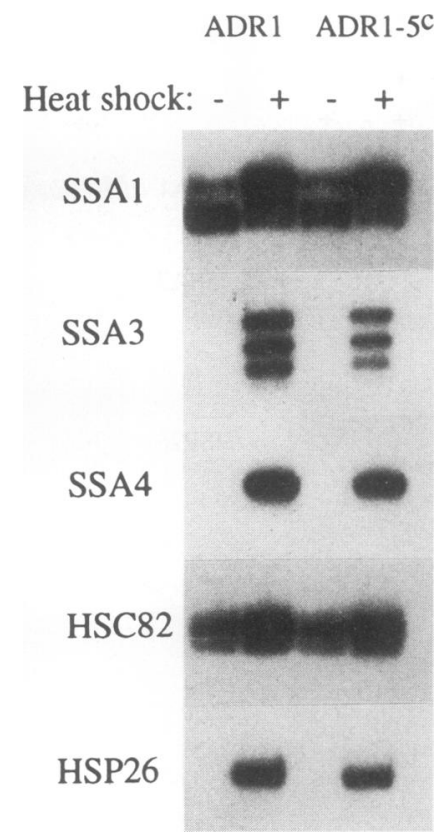

FIG. 9. Analysis of the heat shock response of the $A D R 1-5^{\mathrm{c}}$ mutant. Primer extension analysis of RNA prepared from shocked $(+)$ and nonshocked $(-)$ cells of strains $411-40(A D R 1)$ and $660\left(A D R 1-5^{\mathrm{c}}\right.$ [isogenic to 411-40]) is shown.

16). To examine whether Adr1 could be involved in modulation of hsp gene expression, we used a strain that carries a dominant $A D R 1$ allele, $A D R 1-5^{\mathrm{c}}(16)$. As shown in Fig. 9, not one of the hsp genes tested was induced in the $A D R 1-5^{\mathrm{c}}$ strain under nonshock conditions, suggesting that Adr1 is not a positive regulator of any of them.

hsp gene induction is defective in Ha-Ras-transformed rat fibroblasts. Many aspects of the yeast Ras pathway are similar to the mammalian Ha-Ras pathway $(2,40,62)$. To determine whether mammalian Ha-Ras affects expression of mammalian hsp genes, we measured induction of HSP68 in rat fibroblasts (FR3T3), untransformed or transformed with Ha-ras. As shown in Fig. 10A, expression of rat HSP68 (which is $76 \%$ homologous to yeast $S S A 1$ [37]) was rapidly induced upon heat shock in untransformed FR3T3 cells. This induction reached its peak after 15 min of heat shock. However, no induction of HSP68 was observed in Ha-Ras-transformed FR3T3 cells after 15 min of heat shock. Longer heat shock treatment (45 min) induced HSP68 to a level which was about $10 \%$ of the level in the untransformed cells. The expression levels of the constitutive HSC73 gene were similar in the transformed and untransformed cells and indicated that the decreased induction of HSP68 in Ha-ras-transformed cells is not due to a general effect on RNA metabolism.

Mammalian cells express at least two HSFs which are regulated at several different levels. Activation of mammalian HSFs involves subcellular localization, oligomerization, and other modifications that result in acquisition of DNA binding and transcriptional activities $(57,63)$. We measured the DNA binding activity of HSF in transformed and untransformed FR3T3 cells before and after heat shock. As shown in Fig. 10B, both cell lines exhibited similar levels of inducible HSF binding activity. The possibility that HSF activity is regulated at some level by the Ha-ras pathway cannot be excluded by our results; 


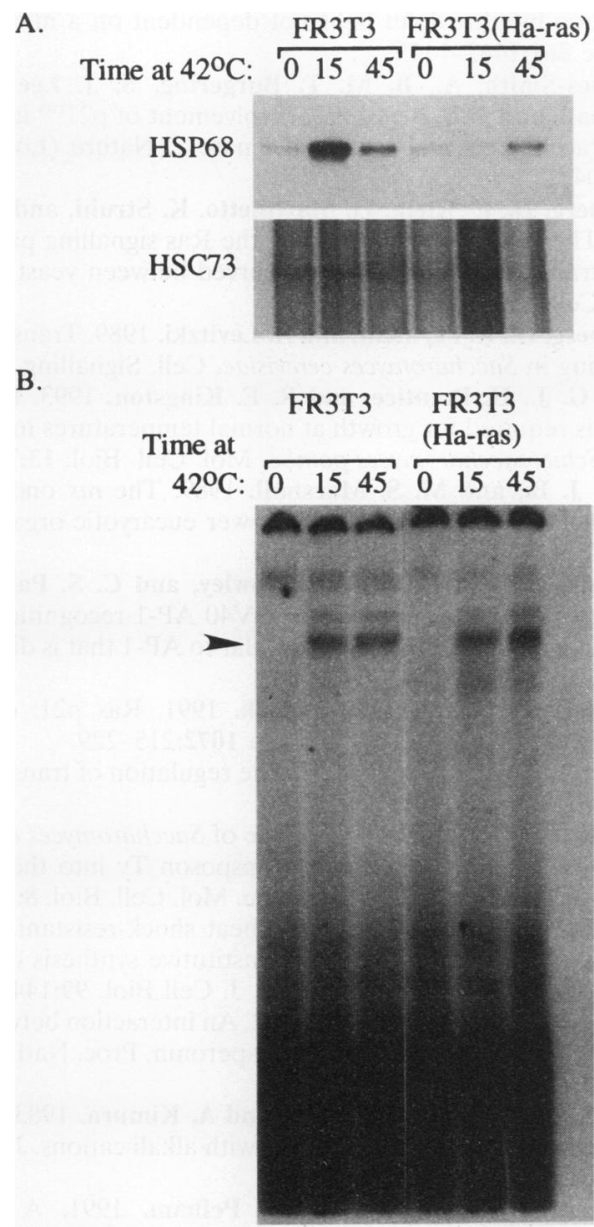

FIG. 10. Analysis of heat shock response in rat fibroblasts. (A) Kinetics of heat shock gene expression in FR3T3 cells transformed (lanes 4 to 6) or not transformed (lanes 1 to 3 ) with Ha-ras. RNAs were prepared at the time point indicated after cells were transferred to heat shock temperature. HSP 68 was assayed by $\mathrm{S} 1$ analysis, and $H S C 73$ was assayed by primer extension. (B) Kinetics of DNA binding activity (bandshift) in nuclear extracts of FR3T3 cells transformed (lanes 4 to 6) or not transformed (lanes 1 to 3) with Ha-ras. Extracts were prepared at the time points indicated after cells were transferred to heat shock temperature.

however, it seems that in FR3T3 cells the major levels of HSF activation are not regulated by the Ha-ras pathway. As in yeast cells, other transcription factors and not HSF may be suppressed by the activation of Ha-ras pathway and prevent normal induction of heat shock genes.

\section{DISCUSSION}

This study shows a strong correlation between effects of the Ras-cAMP pathway on induction of hsp genes and the heatsensitive or heat-resistant phenotypes of mutants in this pathway. The attenuated induction of hsp genes in $R A S 2^{\text {Val-19 }}$ and bcy 1 cells can explain their heat-sensitive phenotype, assuming that increased production of hsps provides protection against heat shock. On the other hand, expression of hsp genes in the cyrl strain, even at $23^{\circ} \mathrm{C}$, provides an explanation for the heat-resistant phenotype of this strain. These findings are consistent with previous observations that cells which express hsp genes prior to heat shock are more resistant to heat shock and other stresses $(27,42,56)$. The fact that removal of cAMP from the media (and induction of heat shock genes) makes cyr1 cells even more resistant to heat shock (65 [and data not shown]) strongly supports this notion. The correlation between heat shock gene expression and resistance or sensitivity phenotypes implies that normal expression of the hsps in the $R A S 2^{\mathrm{Val}-19}$ and $b c y 1$ strains may suppress their sensitivity to heat shock. Testing this idea requires concomitant expression of many different genes, and it is currently not practical. Our similar observation with mammalian cells suggests that the correlation between transformed phenotypes and attenuated heat shock gene expression is universal, and normal expression of these genes in transformed cells may result in reversion of the malignant phenotypes. It is not known what role hsps may play in cell transformation, but the fact that their regulation by Ras is evolutionarily conserved suggests that this role is important. Ha-Ras in mammalian cells was previously shown to be associated with Hsp60 (28), but the physiological role of this association is not clear. It was also reported that cotransfection of $H S C 73$ with Ha-ras and other oncogenes suppresses cellular transformation (84). Collectively, the results from both yeast and mammalian cells suggest that, to transform cells, Ras downregulates heat shock genes.

What is the mechanism by which Ras controls heat shock gene expression? Surprisingly, yHSF is normally expressed and regulated in the various mutant strains, including those in which the heat shock response is severely attenuated. Therefore, the Ras-cAMP pathway is unlikely to control the heat shock response through modification of yHSF. While cAMP depletion led to induction of hsp genes (Fig. 4), it did not result in the characteristic change in yHSF electrophoretic mobility normally observed after heat shock (Fig. 6B). Although the role of this phosphorylation event is not clear (67), these findings suggest that induction due to cAMP depletion is not mediated through the yHSF either. In support of this conclusion, we find that only a subset of hsp genes are induced by cAMP depletion (Fig. 4). The attenuation of hsp induction by activation of the Ras signalling pathway is more general and appears to affect all of the hsp genes that we examined (Fig. 2). This suggests the presence of a common control element in the promoter region of these genes. Since the HSE is the only known cis element common to all of these genes, it is quite puzzling how Ras can control the expression of such a large number of hsps without affecting the activity of yHSF. Boorstein and Craig identified a cAMP-responsive element in the promoter of $S S A 3$ (9). However, this sequence seems to be unique to $S S A 3$ and requires an adjacent HSE for full activity (9). A UAS which is regulated by cPKA has been recently characterized (39) in the promoter of the CTT1 gene. The CTT1 promoter does not contain HSEs, but it was shown to respond to a variety of stress conditions (39). It is possible that the promoters of many hsp genes contain an element with similar properties. Further studies are necessary to identify such elements and to reveal the mechanism by which Ras controls the expression of hsp genes.

The mammalian HSF is able to bind DNA in response to heat shock both in normal and in Ha-ras-transformed FR3T3 cells. Although the possibility remains that the HSF activity is suppressed by the Ha-ras pathway at another level of regulation, it could be that in mammalian cells, as in yeast cells, Ras controls heat shock gene expression through another factor or other factors. More studies of the mechanism of HSF regulation are required to reveal this issue.

The observation that, both in yeasts and in mammals, Ras controls transcription of similar genes is surprising, because in the two systems Ras regulates different biochemical pathways 
(Raf1 and MAP kinases in mammals [43, 73, 77-79, 83, 85] and adenylyl cyclase in yeasts $[12,75])$. Recently, we have shown that both yeast Ras and mammalian Ras activate AP-1 transcription factors (19), providing another example for the similarities between the Ras pathways at the level of gene expression. It could be that many effects of Ras on gene expression are crucial for cellular responses to external signals and therefore are highly conserved in evolution. However, the pathways that transmit the signal from Ras to the transcription factors are not conserved. We propose that $S$. cerevisiae, which is a useful model for the study of Ras signalling $(2,20,40,62)$, is also a relevant model organism for the study of Ras activity at the level of gene expression.

\section{ACKNOWLEDGMENTS}

We thank Michael Wigler, Kunihiro Matsumoto, and Clyde Denis for yeast strains.

D.E. was supported by a fellowship from the Human Frontier Science Program Organization and is now supported by the Israel Cancer Research Fund. This study was supported by NIH grant GM 47381 (to C.S.P.) and by the Beckman Institute at the California Institute of Technology.

\section{REFERENCES}

1. Ausubel, F. M., R. Brent, R. E. Kingston, D. D. Moore, J. G. Seidman, J. A. Smith, and K. Struhl. 1991. Current protocols in molecular biology. Wiley, New York.

2. Ballester, R., T. Michaeli, K. Ferguson, H.-P. Xu, F. McCormick, and M. Wigler. 1989. Genetic analysis of mammalian GAP expressed in yeast. Cell 59:681-686.

3. Barbacid, M. 1987. ras genes. Annu. Rev. Biochem. 56:779-828.

4. Beckner, S. K., S. Hattori, and T. Y. Shih. 1985. The ras oncogene product p21 is not a regulatory component of adenylate cyclase. Nature (London) 317:71-72.

5. Bienz, M., and H. R. B. Pelham. 1987. Mechanisms of heat shock activation in higher eukaryotes. Adv. Genet. 24:31-72.

6. Binetruy, B., T. Smeal, and M. Karin. 1991. Ha-Ras augments c-Jun activity and stimulates phosphorylation of its activation domain. Nature (London) 351:122-127.

7. Bollag, G., and F. McCormick. 1991. Regulators and effectors of ras proteins. Annu. Rev. Cell Biol. 7:601-632.

8. Boorstein, W. R., and E. A. Craig. 1990. Transcriptional regulation of SSA3, an HSP70 gene from Saccharomyces cerevisiae. Mol. Cell. Biol. 10:3262-3267.

9. Boorstein, W. R., and E. A. Craig. 1990. Regulation of a yeast HSP70 gene by a cAMP transcriptional control element. EMBO J. 9:2543-2553.

10. Boorstein, W. R., and E. A. Craig. 1990. Structure and regulation of the SSA4 HSP70 gene of Saccharomyces cerevisiae. J. Biol. Chem. 265:18912-18921.

11. Borkovich, K. A., F. W. Farrelly, D. B. Finkelstein, J. Taulien, and S. Lindquist. 1989. hsp82 is an essential protein that is required in higher concentrations for growth of cells at higher temperatures. Mol. Cell. Biol. 9:3919-3930.

12. Broach, J. R., and R. J. Deschenes. 1990. The function of RAS genes in Saccharomyces cerevisiae. Adv. Cancer Res. 54:79-139.

13. Cherry, J. R., T. R. Johnson, C. Dollard, J. R. Shuster, and C. L. Denis. 1989. Cyclic AMP-dependent protein kinase phosphorylates and inactivates the yeast transcriptional activator $A D R 1$. Cell 56:409-419.

14. Clos, J., T. Westwood, P. B. Becker, S. Wilson, K. Lambert, and C. Wu. 1990. Molecular cloning and expression of a hexameric Drosophila heat shock factor subject to negative regulation. Cell 63:1085-1097.

15. Cunniff, N. F. A., J. Wagner, and W. D. Morgan. 1991. Modular recognition of 5-base-pair DNA sequence motifs by human heat shock transcription factor. Mol. Cell. Biol. 11:3504-3514.

16. Denis, C. L., and E. T. Young. 1983. Isolation and characterization of the positive regulatory gene ADR1 from Saccharomyces cerevisiae. Mol. Cell. Biol. 3:360-370.

17. Devary, Y., C. Rosette, J. A. DiDonato, and M. Karin. 1993. NF-кB activation by ultraviolet light not dependent on a nuclear signal. Science 261:1442-1445.

18. de Vries-Smith, A., B. M. T. Burgering, S. J. Leevers, C. J. Marshall, and J. L. Bos. 1992. Involvement of p21 ${ }^{\text {ras }}$ in activation of extracellular signal-regulated kinase 2. Nature (London) 357: 602-604.

19. Engelberg, D., C. Klein, H. Martinetto, K. Struhl, and M. Karin. 1994. The UV response involving the Ras signalling pathway and AP-1 transcription factors is conserved between yeast and mammals. Cell 77:381-390.

20. Engelberg, D., R. Perlman, and A. Levitzki. 1989. Transmembrane signalling in Saccharomyces cerevisiae. Cell. Signalling 1:1-7.

21. Gallo, G. J., H. Prentice, and R. E. Kingston. 1993. Heat shock factor is required for growth at normal temperatures in the fission yeast Schizosaccharomyces pombe. Mol. Cell. Biol. 13:749-761.

22. Gibbs, J. B., and M. S. Marshall. 1989. The ras oncogene-an important regulatory element in lower eucaryotic organisms. Microbiol. Rev. 53:171-185.

23. Harshman, K. D., W. S. Moye-Rowley, and C. S. Parker. 1988. Transcriptional activation by the SV40 AP-1 recognition element in yeast is mediated by a factor similar to AP-1 that is distinct from GCN4. Cell 53:321-330.

24. Haubruch, H., and F. McCormick. 1991. Ras p21: effects and regulation. Biochim. Biophys. Acta 1072:215-229.

25. Hunter, T., and M. Karin. 1992. The regulation of transcription by phosphorylation. Cell 70:375-387.

26. Iida, H. 1988. Multistress resistance of Saccharomyces cerevisiae is generated by insertion of retrotransposon Ty into the $5^{\prime}$ coding region of the adenylate cyclase gene. Mol. Cell. Biol. 8:5555-5560.

27. Iida, H., and I. Yahara. 1984. A heat shock-resistant mutant of Saccharomyces cerevisiae shows constitutive synthesis of two heat shock proteins and altered growth. J. Cell Biol. 99:1441-1450.

28. Ikawa, S., and R. A. Weinberg. 1992. An interaction between $\mathrm{p} 21^{\text {ras }}$ and heat shock protein hsp60, a chaperonin. Proc. Natl. Acad. Sci. USA 89:2012-2016.

29. Itoh, H., Y. Fukuda, K. Murata, and A. Kimura. 1983. Transformation of intact yeast cells treated with alkali cations. J. Bacteriol. 153:163-168.

30. Jakobsen, B. K., and H. R. B. Pelham. 1991. A conserved heptapeptide restrains the activity of the yeast heat shock transcription factor. EMBO J. 10:369-375.

31. Kataoka, T., S. Powers, C. McGill, O. Fasano, J. Strathern, J. Broach, and M. Wigler. 1984. Genetic analysis of yeast RAS1 and RAS2 genes. Cell 37:437-445.

32. Kurtz, S., J. Rossi, L. Petko, and S. Lindquist. 1986. An ancient developmental induction: heat-shock proteins induced in sporulation and oogenesis. Science 231:1154-1157.

33. Levitzki, A., J. Rudick, I. Pastan, W. C. Vass, and D. R. Lowy. 1986. Adenylate cyclase activity of NIH3T3 cells morphologically transformed by ras genes. FEBS Lett. 197:134-138.

34. Lindquist, S. 1986. The heat-shock response. Annu. Rev. Biochem. 55:1151-1191.

35. Lindquist, S., and E. A. Craig. 1988. The heat shock proteins. Annu. Rev. Genet. 22:631-677.

36. Lis, J., and C. Wu. 1993. Protein traffic on the heat shock promoter: parking, stalling, and trucking along. Cell 74:1-4.

37. Lowe, D. G., and L. A. Moran. 1986. Molecular cloning and analysis of DNA complementary to three mouse $\mathrm{Mr}=68,000$ heat shock protein mRNAs. J. Biol. Chem. 261:2102-2112.

38. Mager, W. H., and P. Moradas Ferreira. 1993. Stress response of yeast. Biochem. J. 290:1-13.

39. Marchler, G., C. Schuller, G. Adam, and H. Ruis. 1993. A Saccharomyces cerevisiae UAS element controlled by protein kinase $A$ activates transcription in response to a variety of stress conditions. EMBO J. 12:1997-2003.

40. Martegani, E., M. Vanoni, R. Zippel, P. Coccetti, R. Brambilla, C. Ferrari, E. Sturani, and L. Albergina. 1992. Cloning by functional complementation of a mouse cDNA encoding a homologue of $C D C 25$, a Saccharomyces cerevisiae $R A S$ activator. EMBO J. 11:2151-2157.

41. Matsumoto, K., I. Uno, and T. Ishikawa. 1985. Genetic analysis of the role of cAMP in yeast. Yeast 1:15-24.

42. McAlistair, L., and D. B. Finkelstein. 1980. Heat shock proteins 
and thermal resistance in yeast. Biochem. Biophys. Res. Commun. 93:819-824.

43. Moodie, S. A., B. M. Willumsen, M. J. Weber, and A. Wolfman. 1993. Complexes of Ras.GTP with Raf-1 and mitogen-activated protein kinase kinase. Science 260:1658-1661.

44. Morimoto, R. I., K. D. Sarge, and K. Abravaya. 1992. Transcriptional regulation of heat shock genes. J. Biol. Chem. 267:2198721990.

45. Nasmyth, K. 1993. Control of the yeast cell cycle by Cdc28 protein kinase. Curr. Opin. Cell Biol. 5:166-179.

46. Nicolet, C. M., and E. A. Craig. 1989. Isolation and characterization of STI1, a stress-inducible gene from Saccharomyces cerevisiae. Mol. Cell. Biol. 9:3638-3646.

47. Nieto-Sotelo, J., G. Wiederrecht, A. Okuda, and C. S. Parker. 1990. The yeast heat shock transcription factor contains a transcriptional activation domain whose activity is repressed under nonshock conditions. Cell 62:807-817.

48. Parsell, D. A., Y. Sanchez, J. D. Stitzel, and S. Lindquist. 1991 Hsp104 is a highly conserved protein with two essential nucleotide-binding sites. Nature (London) 353:270-273.

49. Pelham, H. R. B. 1982. A regulatory upstream promoter element in the Drosophila hsp70 heat-shock gene. Cell 30:517-528.

50. Perisic, O., H. Xiao, and J. T. Lis. 1989. Stable binding of Drosophila heat shock factor to head-to-head and tail-to-tail repeats of a conserved 5 bp recognition unit. Cell 59:797-806.

51. Piper, P. W., B. Curran, M. W. Davis, K. Hirst, A. Lockheart, J. E. Ogden, C. Stanway, A. J. Kingsman, and S. M. Kingsman. 1988. A heat shock element within the phosphoglycerate kinase gene promoter of Saccharomyces cerevisiae. Nucleic Acids Res. 16: 1333-1348.

52. Rabindran, S. K., G. Giorgi, J. Clos, and C. Wu. 1991. Molecular cloning and expression of a human heat shock factor, HSF1. Proc. Natl. Acad. Sci. USA 88:6906-6910.

53. Rabindran, S. K., R. I. Raymond, I. Haroun, J. Clos, J. Wisniewski, and C. Wu. 1993. Regulation of heat shock factor trimer formation: role of a conserved leucine zipper. Science 259:230-234

54. Rose, M. D., F. Winston, and P. Hieter. 1990. Methods in yeast genetics. Cold Spring Harbor Laboratory Press, Cold Spring Harbor, N.Y.

55. Sambrook, J., E. F. Fritsch, and T. Maniatis. 1989. Molecular cloning: a laboratory manual, 2nd ed. Cold Spring Harbor Laboratory Press, Cold Spring Harbor, N.Y.

56. Sanchez, Y., and S. L. Lindquist. 1990. HSP104 required for induced thermotolerance. Science 248:1112-1115.

57. Sarge, K. D., S. P. Murphy, and R. I. Morimoto. 1993. Activation of heat shock gene transcription by heat shock factor 1 involves oligomerization, acquisition of DNA-binding activity, and nuclear localization and can occur in the absence of stress. Mol. Cell. Biol. 13:1392-1407.

58. Sass, P., J. Field, J. Nikawa, T. Toda, and M. Wigler. 1986. Cloning and characterization of the high-affinity cAMP phosphodiesterase of Saccharomyces cerevisiae. Proc. Natl. Acad. Sci. USA 83:9303-9307.

59. Satoh, T., M. Nakafuku, and Y. Kaziro. 1992. Function of Ras as a molecular switch in signal transduction. J. Biol. Chem. 267: 24149-24152.

60. Scharf, K.-D., S. Rose, W. Zott, F. Schoff, and L. Nover. 1990. Three tomato genes code for heat stress transcription factors with a region of remarkable homology to the DNA-binding domain of the yeast HSF. EMBO J. 9:4495-4501.

61. Schuetz, T. J., G. J. Gallo, L. Sheldon, P. Tempst, and R. E. Kingston. 1991. Isolation of a cDNA for HSF2: evidence for two heat shock factor genes in humans. Proc. Natl. Acad. Sci. USA 88:6911-6915.

62. Segal, M., I. Marbach, D. Engelberg, G. Simchen, and A. Levitzki. 1992. Interaction between the Saccharomyces cerevisiae CDC25 gene product and mammalian Ras. J. Biol. Chem. 267:2274722751.

63. Sheldon, L. A., and R. E. Kingston. 1993. Hydrophobic coiled-coil domains regulate the subcellular localization of human heat shock factor 2. Genes Dev. 7:1549-1558.

64. Shilo, V., G. Simchen, and B. Shilo. 1978. Initiation of meiosis in cell cycle initiation mutants of Saccharomyces cerevisiae. Exp. Cell Res. 112:241-248.

65. Shin, D.-Y., K. Matsumoto, H. Iida, I. Uno, and T. Ishikawa. 1987. Heat shock response of Saccharomyces cerevisiae mutants altered in cyclic AMP-dependent protein phosphorylation. Mol. Cell. Biol. 7:244-250.

66. Slater, M. R., and E. A. Craig. 1989. The SSA1 and SSA2 genes of the yeast Saccharomyces cerevisiae. Nucleic Acids Res. 17:805-806.

67. Sorger, P. K. 1991. Heat shock factor and heat shock response. Cell 65:363-366.

68. Sorger, P. K., M. J. Lewis, and H. R. B. Pelham. 1987. Heat shock factor is regulated differently in yeast and HeLa cells. Nature (London) 329:81-84.

69. Sorger, P. K., and H. R. B. Pelham. 1987. Cloning and expression of a gene coding hsc73, the major hsp70-like protein in unstressed rat cells. ЕMBO J. 6:993-998.

70. Sorger, P. K., and H. R. B. Pelham. 1988. Yeast heat shock factor is an essential DNA-binding protein that exhibits temperaturedependent phosphorylation. Cell 54:855-864.

71. Susek, R. E., and S. L. Lindquist. 1989. hsp26 of Saccharomyces cerevisiae is related to the superfamily of small heat shock proteins but is without a demonstrable function. Mol. Cell. Biol. 9:52655271.

72. Tanaka, K., K. Matsumoto, and A. Toh-e. 1988. Dual regulation of the expression of the polyubiquitin gene by cyclic AMP and heat shock in yeast. EMBO J. 7:495-502.

73. Thomas, S. M., M. Demarco, G. D'arcangelo, S. Halegoua, and J. S. Brugge. 1992. Ras is essential for nerve growth factor- and phorbol ester-induced tyrosine phosphorylation of MAP kinase. Cell 68:1031-1040.

74. Toda, T., S. Cameron, P. Sass, M. Zoller, J. D. Scott, B. McMullen, M. Hurwitz, E. G. Krebs, and M. Wigler. 1987. Cloning and characterization of $B C Y 1$, a locus encoding a regulatory subunit of the cyclic AMP-dependent protein kinase in Saccharomyces cerevisiae. Mol. Cell. Biol. 7:1371-1377.

75. Toda, T., I. Uno, T. Ishikawa, S. Powers, T. Kataoka, D. Broek, S. Cameron, J. Broach, K. Matsumoto, and M. Wigler. 1985. In yeast, RAS proteins are controlling elements of adenylate cyclase. Cell 40:27-36.

76. Topol, J., D. M. Ruden, and C. S. Parker. 1985. Sequences required for in vitro transcriptional activation of a Drosophila hsp70 gene. Cell 42:527-537.

77. Van Aelst, L., M. Barr, S. Marcus, A. Polverino, and M. Wigler. 1993. Complex formation between RAS and RAF and other protein kinases. Proc. Natl. Acad. Sci. USA 90:6213-6217.

78. Vojtek, A. B., S. M. Hollenberg, and J. A. Cooper. 1993. Mammalian Ras interacts directly with the serine/threonine kinase Raf. Cell 74:205-214.

79. Warne, P. H., P. R. Viciana, and J. Downward. 1993. Direct interaction of Ras and the amino-terminal region of Raf-1 in vitro. Nature (London) 364:352-355.

80. Werner-Washburne, M., J. Becker, J. Kosic-Smithers, and E. A. Craig. 1989. Yeast Hsp70 RNA levels vary in response to the physiological status of the cell. J. Bacteriol. 171:2680-2688.

81. Westwood, J. T., J. Clos, and C. Wu. 1991. Stress-induced oligomerization and chromosomal relocalization of heat-shock factor. Nature (London) 353:822-827.

82. Wiederrecht, G., D. Seto, and C. S. Parker. 1988. Isolation of the gene encoding the $S$. cerevisiae heat shock transcription factor. Cell 54:841-853.

83. Williams, N. G., H. Paradis, S. Agarwal, D. L. Charest, S. L. Pelech, and T. M. Roberts. 1993. Raf-1 and p21 v-ras cooperate in the activation of mitogen-activated protein kinase. Proc. Natl. Acad. Sci. USA 90:5772-5776.

84. Yehiely, F., and M. Oren. 1992. The gene for the rat heat-shock cognate, hsc70, can suppress oncogene-mediated transformation. Cell Growth Differ. 3:803-809.

85. Zhang, X.-F., J. Settleman, J. M. Kyriakis, E. Takeuchi-Suzuki, S. J. Elledge, M. S. Marshall, J. T. Bruder, U. R. Rapp, and J. Avruch. 1993. Normal and oncogenic p21 $1^{\text {ras }}$ proteins bind to the amino-terminal regulatory domain of c-Raf-1. Nature (London) 364:308-313. 